\title{
Dos excessos da TV generalista: Retratos da informação semanal emitida em horário nobre
}

Felisbela Lopes

\begin{abstract}
Resumo
Apesar de a esfera pública da nossa sociedade ter sofrido várias metamorfoses, de modo a incorporar novas realidades, a programação jornalística não soube acompanhar estas evoluções. Este artigo pretende analisar a programação informativa dos vários canais generalistas, emitida em horário nobre, e a sua evolução desde 1993 até 2005. Debater-se-ão algumas das tendências em termos de oferta televisiva, como a clonagem de formatos televisivos, a oferta monotemática, a submissão dos programas informativos a uma lógica comercial de luta pelas audiências. Perante este panorama, qual o futuro do jornalismo televisivo? E onde fica, perante uma lógica mercantilista, o interesse comum?
\end{abstract}

Palavras-chave: informação, televisão, programação

À data em que escrevemos este texto, a Lei da Televisão em vigor (Lei n. ${ }^{\circ}$ 32/2003, de 22 de Agosto) estipula que um canal generalista deverá ter os seguintes fins:

“a) Contribuir para a informação, formação e entretenimento do público;

b) Promover o exercício do direito de informar e de ser informado, com rigor e independência, sem impedimentos nem discriminações;

c) Favorecer a criação de hábitos de convivência cívica própria de um Estado democrático e contribuir para o pluralismo político, social e cultural;

d) Promover a cultura e a língua portuguesas e os valores que exprimem a identidade nacional."

\footnotetext{
* Investigadora do CECS e Professora Auxiliar do Departamento de Ciências da Comunicação do Instituto de Ciências Sociais da Universidade do Minho (felisbela@ics.uminho.pt)
} 
A formulação é genérica, como seria, aliás, de esperar de qualquer articulado deste género. No entanto, estranha-se que nada seja dito relativamente à composição da grelha. Nem mesmo o Contrato de Concessão de Serviço Público de Televisão, assinado a 22 de Setembro de 2003 e abrangendo apenas a RTP, tem orientações nesse sentido. Neste contexto, dir-se-á que os canais de televisão podem fazer (quase) tudo. Não podem, porque a sua natureza generalista lhes impõe uma oferta diversificada e a legislação do sector dos media coloca entraves a algumas opções. Mas, na prática, o espaço de liberdade é amplo, permitindo que as estações privadas sejam, em horário nobre, canais temáticos de entretenimento. Por altura da renovação das licenças de televisão da SIC e da TVI, tivemos a oportunidade de chamar reiteradamente a atenção para a programação televisiva que estes dois canais privados apresentavam em horário nocturno. Logo após a estreia do Big Brother, a TVI rendeu-se às "novelas da vida real" e à ficção nacional. A SIC tentou clonar muitos dos formatos do canal quatro, enchendo as franjas nocturnas ora com novos reality shows, ora com novelas (portuguesas e/ou brasileiras). Este rumo colocava naturalmente em causa a natureza generalista das estações privadas e, sobretudo, os projectos que haviam sido aprovados, a 8 de Agosto de 1991, pela entidade reguladora, na altura a Alta Autoridade para a Comunicação Social (AACS). Nestes quinze anos, as grelhas mudaram substancialmente ao ponto de tornarem irreconhecíveis os projectos iniciais de ambos os canais privados, mas de concessão pública. É certo que nunca houve da parte das entidades competentes um escrutínio sistemático daquilo que estava a ser feito. Todavia, depois de um período de relativa letargia da AACS, o órgão que lhe sucedeu, a Entidade Reguladora da Comunicação Social (ERC), não deixou passar o processo de renovação das licenças de televisão sem a apresentação de um documento que fixa algumas linhas orientadoras para a SIC e para a TVI. Na (extensa) deliberação 1-L/2006 com a data de 20 de Junho (102 páginas), a ERC estabelece os fundamentos da sua decisão de renovar as licenças aos operadores privados, afirmando que, "relativamente a algumas obrigações assumidas pelos operadores televisivos - quer por decorrência directa da lei, quer porque a isso se comprometeram na apresentação da respectiva candidatura (em 1990) ou em momento posterior - se verifica um cumprimento pouco satisfatório". Salientam-se alguns aspectos de incumprimento.

Da parte da SIC:

- diminuição progressiva do número de jornais informativos: quatro em 1990, três em 1999, dois em 2005;

- desaparecimento de programas especializados no campo da reportagem nacional e internacional, da entrevista e do debate com autonomia relativamente aos blocos informativos das $13 \mathrm{~h} 00$ e das $20 \mathrm{~h} 00$, em claro incumprimento dos compromissos assumidos em 1999;

- eliminação do flash informativo diário, contemplado no projecto de 1999;

- emissões destinadas a públicos infantis remetidas para horários pouco adequados, de segunda a sexta e desaparecidos da grelha de programas em 2006; 
- programação cultural com presença reduzida na grelha e emitida em horários de audiência diminuta.

Da parte da TVI:

- emissões destinadas a públicos infantis remetidas para o fim-de-semana. O compromisso assumido em 1999 envolvia a emissão de programas infantis nas manhãs de segunda a domingo e nas tardes dos dias úteis;

- programação cultural esporádica e emitida em horários de audiência reduzida. Apesar de o projecto de 1999 não contemplar programação cultural, assumia-se como um projecto com preocupações de natureza cultural;

- ausência de programas especializados no campo da reportagem nacional e internacional, da entrevista e do debate, autónomos em relação aos blocos informativos das $13 \mathrm{~h} 00$ e das 20h00, em claro incumprimento dos compromissos assumidos em 1999;

- eliminação do flash informativo diário contemplado no projecto de 1999.

Quase meio ano após esta deliberação, os canais privados generalistas ainda não procederam a uma renovação da sua engenharia de programação de horário nobre.

Veja-se, a título de exemplo, o Quadro 1.

Quadro 1: Oferta televisiva dos canais generalistas em horário nobre (21h00-00h00) Semana de 27 de Novembro a 1 de Dezembro de 2006

\begin{tabular}{|c|c|c|c|}
\hline & RTP & SIC & TVI \\
\hline $\begin{array}{l}\text { Segunda- } \\
\text {-feira }\end{array}$ & $\begin{array}{l}\text { 21h00 Notas Soltas (comentário) } \\
\text { 21h00 Um Contra Todos (concurso) } \\
\text { 22h15 Contra-Informação } \\
\text { 22h30 Prós e Contras (debate) }\end{array}$ & $\begin{array}{l}\text { 21h15 Floribella (novela) } \\
\text { 22h15 Cobras \& Lagartos (novela) } \\
\text { 23h15 Jura (novela) }\end{array}$ & $\begin{array}{l}\text { 21h15 Doce Fugitiva (novela) } \\
\text { 22h00 Tempo de Viver (novela) } \\
\text { 22h45 Eu e Tu (novela) } \\
\text { 23h45 Pedro, o Milionário (reality } \\
\text { show) }\end{array}$ \\
\hline $\begin{array}{l}\text { Terça- } \\
\text {-feira }\end{array}$ & $\begin{array}{l}\text { 21h00 Especial Informação (debate) } \\
\text { 22h00 Um Contra Todos (concurso) } \\
\text { 23h15 Sessão da Noite (cinema) }\end{array}$ & $\begin{array}{l}\text { 21h15 Floribella (novela) } \\
\text { 22h15 Cobras \& Lagartos (novela) } \\
\text { 23h15 Jura (novela) }\end{array}$ & $\begin{array}{l}\text { 21h15 Doce Fugitiva (novela) } \\
\text { 22h15 Tempo de Viver (novela) } \\
\text { 23h15 Eu e Tu (novela) } \\
\text { 23h45 Dr. House (série estrangeira) }\end{array}$ \\
\hline $\begin{array}{l}\text { Quarta- } \\
\text {-feira }\end{array}$ & $\begin{array}{l}\text { 21h00 Em Reportagem } \\
\text { 22h15 Contra-Informação } \\
\text { 22h30 Real Companhia (document.) } \\
\text { 23h30 Sessão da Meia-Noite } \\
\text { (cinema) }\end{array}$ & $\begin{array}{l}\text { 21h15 Floribella (novela) } \\
\text { 22h15 Cobras \& Lagartos (novela) } \\
\text { 23h15 Jura (novela) }\end{array}$ & $\begin{array}{l}\text { 21h15 Doce Fugitiva (novela) } \\
\text { 22h15 Tempo de Viver (novela) } \\
\text { 23h15 Eu e Tu (novela) } \\
\text { 00h15 Dr. House (série estrangeira) }\end{array}$ \\
\hline $\begin{array}{l}\text { Quinta- } \\
\text {-feira }\end{array}$ & $\begin{array}{l}\text { 21h00 Grande Entrevista } \\
\text { 21h30 Um Contra Todos (concurso) } \\
\text { 22h30 Contra-Informação } \\
\text { 22h45 Principal Suspeito (série) }\end{array}$ & $\begin{array}{l}\text { 21h15 Floribella (novela) } \\
\text { 22h15 Cobras \& Lagartos (novela) } \\
\text { 23h15 Jura (novela) }\end{array}$ & $\begin{array}{l}\text { 21h15 Doce Fugitiva (novela) } \\
\text { 22h15 Tempo de Viver (novela) } \\
\text { 23h15 Eu e Tu (novela) }\end{array}$ \\
\hline $\begin{array}{l}\text { Sexta- } \\
\text {-feira }\end{array}$ & $\begin{array}{l}\text { 21h00 Cuidado com a Língua } \\
\text { 21h15 A Voz do Cidadão } \\
\text { 21h30 Contra-Informação } \\
\text { 21h45 Um Contra Todos (concurso) } \\
\text { 22h45 Jogo de Espelhos (inform.) }\end{array}$ & $\begin{array}{l}\text { 21h15 Floribella (novela) } \\
\text { 22h15 Cobras \& Lagartos (novela) } \\
\text { 23h15 Jura (novela) }\end{array}$ & $\begin{array}{l}\text { 21h15 Doce Fugitiva (novela) } \\
\text { 22h30 Tempo de Viver (novela) } \\
\text { 23h30 Eu e Tu (novela) }\end{array}$ \\
\hline
\end{tabular}


Numa leitura genérica do Quadro 1, salienta-se o facto de o canal generalista de serviço público apresentar uma oferta diversificada quer ao nível da informação, quer ao nível do entretenimento. Mantendo diariamente no ar um concurso de cultura geral (Um Contra Todos), a RTP1 abre o horário nobre com programas de informação de diferentes géneros (comentário político à segunda-feira, debate à terça-feira, grande reportagem à quarta-feira, grande entrevista à quinta-feira e programa cultural à sexta-feira). A SIC, de segunda a sexta-feira, preenche o seu serão com três telenovelas, apresentadas em formato sanduíche: novela portuguesa + novela brasileira + novela portuguesa. A TVI enche as suas noites com três telenovelas portuguesas. Como poderão os canais privados reclamar a sua natureza generalista, quando nas franjas de maior audiência se limitam a uma oferta monotemática?

As nossas considerações sobre a TV generalista, que poderiam estender-se à constante contra-programação dos canais privados e ao excesso de informação política do canal público, resultam da análise de um reduzido corte temporal que poderá naturalmente ser posto em causa. Por isso, defendemos que uma reflexão mais consistente sobre a oferta televisiva deve fazer-se a partir de estudos construídos sob bases metodológicas que confiram credibilidade aos resultados obtidos. Na nossa tese de doutoramento (Lopes, 2005), estudámos a informação semanal da RTP1, SIC e TVI entre 1993 e 2003, tendo depois alargado esse período até 2005. Os dados que daí resultam consubstanciam um retrato feito de excessos.

Considerada inicialmente como uma prioridade, a programação informativa dos canais generalistas emitida em horário nocturno e feita ao ritmo semanal foi sendo progressivamente desvalorizada pelos programadores ao longo dos primeiros treze anos de coabitação entre os sectores público e privado. Por outro lado, entre 1993 e 2005 os programas de debate e de grande entrevista foram, sobretudo, espaços de reprodução dos poderes dominantes, circunscritos às elites. Neste período, os estúdios televisivos encheram-se com os mesmos "confrades" que saltavam de canal em canal e de programa em programa. Para além de insistirem em determinadas pessoas, esses programas de informação inclinaram-se para um certo perfil de convidados: políticos, “engenheiros do social” (sociólogos, psis, académicos da área das Ciências Sociais...) e, em certos casos, actores das indústrias culturais. Com isso, reduziu-se o espaço televisivo a um conjunto restrito de pessoas a quem se deu o direito a debater assuntos que ganhavam aí o estatuto público. Desse processo, exclui-se o cidadão comum enquanto interlocutor que opina, que propõe e que se opõe. A sua presença, nestes anos, limitou-se praticamente a depoimentos, ilustrativos de temáticas em discussão.

\section{A informação televisiva feita ao ritmo semanal: um prisma da sociedade contemporânea}

Do nosso estudo da informação semanal dos canais generalistas resulta uma configuração do espaço público que ficou muito aquém do ideal de esfera pública idealizada 
por Jürgen Habermas (1986) no que esse modelo reunia de melhor: um espaço de discussão de assuntos públicos, sem restrição de pessoas e aberto a todos os temas de interesse comum, distinto do Estado e independente de interesses económicos. Poder-se-iam encontrar pontos de contacto com o modelo do filósofo alemão em dois traços que, no entanto, encaramos como as suas grandes limitações: a centralidade de temas urbanos e a exclusão/afastamento das mulheres e dos plebeus dos palcos de encenação da palavra pública. Não é nosso propósito propor a reabilitação do conceito habermasiano de esfera pública, até porque o respectivo desenho é tributário de um tempo que sobrestimava os efeitos dos media e negligenciava as capacidades de negociação dos receptores. Por outro lado, o espaço público actual passa por instituições e repertórios de acção simbólica substancialmente diferentes daqueles de outrora. Significa isso que é necessário pensar novas articulações para o redimensionamento entre o público e o privado, encarando como imprescindível a reabilitação de uma esfera pública que preserve a função crítica da sociedade e, consequentemente, institucionalize a democracia. A esse nível, os territórios electrónicos assumem, hoje mais do que no passado, um posicionamento central.

Confrontada com a crescente complexidade das sociedades modernas que conduziu o espaço público para novos domínios e competências, a informação televisão tem reflectido essa mudança? Face a um espaço público cada vez mais privatizado e a uma esfera privada cada vez mais publicitada, a gestão do consenso social tem acompanhado essa crescente complexidade? Estarão os jornalistas que trabalham em televisão preparados para a enunciação de novas realidades e disporão de recursos suficientes para reter os traços distintivos do seu trabalho? A análise da evolução da oferta informativa semanal dos canais generalistas portugueses entre 1993 e 2005 não permite responder positivamente a estas questões. Nesse período, a TV foi essencialmente uma arena discursiva caracterizada por relações de dominação e de subordinação, sem assinaláveis rasgos inovadores. Reflectindo acerca das novas fronteiras entre o público e o privado, Victoria Camps (1998: 96) defende que “o interesse comum não é algo que se encontre lá fora à espera de ser reconhecido e identificado, mas algo que devemos ir descobrindo através de um diálogo o mais democrático possível”. Este ponto de vista, que partilhamos, exige plataformas colectivas que a informação televisiva, nomeadamente os debates e as grandes entrevistas, pode dinamizar. A participação alargada em discussões sobre questões públicas ou problemáticas do domínio privado, mas de interesse público, sejam elas de preocupação maioritária ou minoritária, não teve, nos anos 90, grande espaço televisivo na informação semanal dos canais generalistas e, nos primeiros cinco anos do século XXI, registou mesmo um revés: a SIC e a TVI foram fazendo desaparecer esse tipo de programação do horário nobre e a RTP1 circunscreveu-a à esfera política. Acontece que, hoje, mais do que num passado recente, as alterações de fronteira entre o público e o privado desencadeiam novos temas, que, no entanto, poderão confrontar-se com um problema de fundo: a incapacidade de inscrição no espaço público. No ensaio intitulado Portugal Hoje, José Gil (2005: 26) traça, a este respeito, um diagnóstico devastador: 
“Não há espaço público porque este está nas mãos de umas quantas pessoas cujo discurso não faz mais do que alimentar a inércia e o fechamento sobre si próprio da estrutura de relações de força que elas representam. Os lugares, tempos, dispositivos mediáticos e pessoas formam um pequeno sistema estático que trabalha afanosamente para a sua manutenção.”

Concebendo o audiovisual como um meio estruturante do espaço público contemporâneo, ou seja, como um meio que engendra um território que poderá ser partilhado por um número significativo de pessoas que se juntam à volta de questões de interesse geral, poder-se-á perguntar: a TV na sua vertente informativa terá capacidade para "inscrever" um espaço público que adquire permanentemente novas configurações? Em teoria, a resposta é positiva, mas, entre 1993 e 2005, a informação semanal dos canais generalistas portugueses não se consubstanciou, de forma sistemática, como um espaço reprodutor de um acervo de conhecimentos, impulsionador de novas formas de vida e promotor de elos sociais. Talvez não tivessem sido os coordenadores e apresentadores dos programas de debate e de grande entrevista que mais falharam: $o$ desenho de grande parte dos espaços informativos não suscitaria muitas reservas, se fosse complementado com outros formatos. Talvez tivessem sido os responsáveis pela programação que se revelaram incapazes de reconstituir uma outra estrutura a uma grelha cada vez mais dispersa para territórios do entretenimento, nomeadamente nas estações privadas.

\section{O afunilamento dos serões da SIC e da TVI numa oferta monotemática}

Cedendo cada vez mais espaço ao entretenimento, a informação semanal acabou por desaparecer da TVI e da SIC no período pós-Big Brother (depois de Setembro de 2000), circunscrevendo-se aos géneros clássicos do debate, da grande entrevista e da grande reportagem na RTP1. Poder-se-ia perguntar qual a diferença que o serviço público, nos primeiros treze anos de coabitação com os canais privados, pode reivindicar para si ao nível da programação informativa. Nesse tempo, o canal público generalista não apresentou rasgos de originalidade que renovassem formas de enunciação da realidade, que reflectissem aquilo que é importante em diversos domínios e alargassem, de facto, o espaço televisivo. A RTP1 ficou aquém de uma informação diversificada, aberta a diferentes sectores sociais e criadora de novas formas de mediatização da realidade; a SIC desistiu rapidamente daquilo que parecia ser um projecto de informação consistente e original; e a TVI, quando saiu da crise em que mergulhou até 1998 e conquistou alguma visibilidade junto das audiências, preferiu apostar na área do entretenimento.

Tendo como pano de fundo o período compreendido entre 1993 e 2005, analisámos com mais pormenor os seguintes anos: 1993, 1996, 1998, 2001 e 2003. Nesse tempo, os debates/grandes entrevistas e os formatos desportivos dominaram a programação informativa semanal nos três canais televisivos generalistas em termos de número de emissões, tendo sido na RTP1 que registaram maior longevidade. Na fase 
pós-Big Brother, a TVI e a SIC foram preenchendo o respectivo horário nobre com entretenimento, desalojando progressivamente a informação semanal dos seus serões. Tal opção configurava uma grelha monotemática, que contrariava a natureza generalista que as respectivas licenças de concessão pública lhes impunham. Comparando, por exemplo, a oferta televisiva de 1993 com a de 2003, há diferenças substanciais. Porque o país mudou? Também, mas sobretudo porque as escolhas dos directores da RTP, da SIC e da TVI, condicionadas pelas audiências, se alteraram radicalmente. Paralelamente ao consumo televisivo, as estações generalistas foram particularmente sensíveis à oferta da concorrência, o que fez desencadear, ao nível da informação semanal, determinados ciclos temáticos (emissões de casos de polícia, formatos de grande reportagem, programas desportivos de debate...). Nos anos que destacámos, foi a SIC que mais inovou nos formatos informativos, mas foi a RTP1 a mais regular na emissão desses géneros televisivos, os quais, na fase dos novos reality shows tipo Big Brother, foram desaparecendo das estações privadas. A TVI nunca fez dessa programação uma aposta sua: em tempo de crise, que se prolongou de 1993 até 1998, apresentou uma oferta instável, incapaz de se implantar junto dos telespectadores; em tempo de liderança de audiências (posterior à estreia do Big Brother), preferiu construir uma grelha que, depois do noticiário das 20h00, se dividia entre reality shows e ficção nacional.

Pelo Quadro 2, constatamos que, ao longo deste tempo, os programadores se mostraram mais sensíveis a conteúdos conhecidos e aceites pelas audiências do que a formatos que mediatizavam novas áreas e que, por isso, exigiam algum risco. Se os canais de televisão foram renovando substancialmente a sua oferta televisiva de entretenimento, o mesmo não se passou com a informação televisiva. As principais inovações ocorreram até finais do primeiro quinquénio dos anos 90, altura a partir da qual os três canais generalistas deixaram de apresentar novidades, com excepção de Ficheiros Clínicos, que surgiu no horário nobre da SIC em Agosto de 1998. O sucesso audimétrico deste inovador formato não teve, porém, força suficiente para animar os programadores a investir neste tipo de oferta televisiva, como haviam feito nos primeiros anos da década.

Poder-se-ia dizer que os ciclos temáticos que a informação semanal foi desenhando nos ecrãs de televisão se implantaram graças ao interesse que o público manifestava através das audiências. Houve o tempo dos programas que incidiam em questões económicas e de política internacional que desapareceram do horário nobre a partir de 1996; o tempo dos programas culturais que vingaram a meio da década 90; o tempo dos casos de polícia que chegaram ao limiar do ano 2000; o tempo dos programas de desporto que conseguiram dobrar o século para desaparecer em seguida. Todas essas temáticas conseguiram audiências razoáveis e fomentaram formatos-clone, pelo menos noutra estação. Há, no entanto, uma excepção. Em Agosto de 1998, a SIC estreou, em horário nobre, Ficheiros Clínicos, que teve mais duas edições, uma em 1999 e a outra em 2002. Tratava-se de um programa, apresentado e coordenado pela jornalista Cláudia Borges, que destacava casos de doenças graves que a Medicina portuguesa resolvia com êxito. Este foi um dos programas de informação mais vistos entre 1993 
Quadro 2: Oferta televisiva ao nível da informação semanal dos canais generalistas

\begin{tabular}{|c|c|c|c|c|c|c|}
\hline Programas & Canais & 1993 & 1996 & 1998 & 2001 & 2003 \\
\hline \multirow{3}{*}{$\begin{array}{l}\text { Entrevistas/ } \\
\text { Debates } \\
\text { generalistas }\end{array}$} & RTP & & & & & \\
\hline & SIC & & & & & \\
\hline & TVI & & & & & \\
\hline \multirow{3}{*}{ Talk-shows } & RTP & & & & & \\
\hline & SIC & & & & & \\
\hline & TVI & & & & & \\
\hline \multirow{3}{*}{$\begin{array}{c}\text { Grande } \\
\text { Reportagem }\end{array}$} & RTP & & & & & \\
\hline & SIC & & & & & \\
\hline & TVI & & & & & \\
\hline \multirow{3}{*}{$\begin{array}{l}\text { Programas } \\
\text { de Desporto }\end{array}$} & RTP & & & & & \\
\hline & SIC & & & & & \\
\hline & TVI & & & & & \\
\hline \multirow{3}{*}{$\begin{array}{l}\text { Programas } \\
\text { de Economia }\end{array}$} & RTP & & & & & \\
\hline & SIC & & & & & \\
\hline & TVI & & & & & \\
\hline \multirow{3}{*}{$\begin{array}{l}\text { Programas de } \\
\text { Questões } \\
\text { Internacionais }\end{array}$} & RTP & & & & & \\
\hline & SIC & & & & & \\
\hline & TVI & & & & & \\
\hline \multirow{3}{*}{$\begin{array}{c}\text { Programas } \\
\text { de Casos } \\
\text { de Polícia }\end{array}$} & RTP & & & & & \\
\hline & SIC & & & & & \\
\hline & TVI & & & & & \\
\hline \multirow{3}{*}{$\begin{array}{c}\text { Programas de Artes/ } \\
\text { Cultura }\end{array}$} & RTP & & & & & \\
\hline & SIC & & & & & \\
\hline & TVI & & & & & \\
\hline \multirow{3}{*}{$\begin{array}{l}\text { Programas sobre } \\
\text { Infância/ } \\
\text { Juventude }\end{array}$} & RTP & & & & & \\
\hline & SIC & & & & & \\
\hline & TVI & & & & & \\
\hline \multirow{3}{*}{$\begin{array}{c}\text { Programas } \\
\text { sobre Ambiente }\end{array}$} & RTP & & & & & \\
\hline & SIC & & & & & \\
\hline & TVI & & & & & \\
\hline \multirow{3}{*}{$\begin{array}{l}\text { Programas } \\
\text { de Saúde }\end{array}$} & RTP & & & & & \\
\hline & SIC & & & & & \\
\hline & TVI & & & & & \\
\hline \multirow{3}{*}{ Outros" } & RTP & & & & & \\
\hline & SIC & & & & & \\
\hline & TVI & & & & & \\
\hline
\end{tabular}

* Programas aí inseridos: Caixa de Perguntas, Na Maior e Janelas Virtuais (1993, TVI); Filhos da Nação (1998, SIC); Bombástico, Escândalos e Boatos, O Crime não Compensa (2003, SIC); Eu Confesso (2003, TVI). 
e 2003, mas esse êxito e o interesse público das emissões não foram suficientes para que a RTP ou a TVI apostassem num formato idêntico ${ }^{1}$. Poder-se-á avançar algumas explicações: Ficheiros Clínicos surgiu num tempo em que a TVI havia adoptado uma linha editorial popular, vocacionada para um jornalismo centrado em casos atravessados pelos traços do "escândalo" ou da "falha", enquanto a RTP vivia um período instável, sucedendo na Direcção da empresa responsáveis que aí permaneciam por um período curto de tempo.

\section{Um espaço público televisivo redutor nas temáticas e elitista nos convidados}

Considerando-se que a informação televisiva ajuda a desenhar o espaço público contemporâneo, os temas que esses programas tratam assumem particular importância. Ao inscreverem determinados assuntos em emissões informativas de debate ou de grande entrevista, os jornalistas situam as discussões num quadro particular de acção, criando ágoras mediáticas (teoricamente) abertas à discussão de múltiplas questões com um conjunto diversificado de interlocutores. Percorrendo os assuntos que constituíram o mote para esses géneros televisivos, nota-se, em certos períodos, uma tendência para discutir uma paleta reduzida de tópicos com convidados circunscritos a grupos de elite. Entre 1993 e 2005, a informação televisiva silenciou muitos temas e interlocutores. Porque estavam nas margens; porque, na ausência de atenção mediática, foram sendo minimizados pela opinião pública; ou porque os canais generalistas não estavam interessados nesse tipo de discussão. Por exemplo: o ambiente, as inovações tecnológicas, o desenvolvimento científico e, curiosamente, os próprios media nunca foram alvo de grande destaque nos debates televisivos. Também foram muitos os grupos sociais que ficaram longe dos plateaux informativos, principalmente pessoas com profissões técnicas, investigadores de ciências exactas, jovens e, sobretudo, o cidadão comum, aquele que não fala em nome de uma profissão ou grupo social, mas que poderia ser convidado a exercer um direito fundamental: o de cidadania, o de participação na res publica.

De acordo com Umberto Eco (1993), a era da privatização dos canais televisivos corresponderia a uma nova fase, designada por "neotelevisão", que seguiria um modelo de programação entendido como um "espelho do quotidiano" dos telespectadores. No que diz respeito aos programas de informação semanal, não houve, entre 1993 e 2005, emissões capazes de implantar essa tal TV espelho de forma contínua e abrangente. Ao longo desse tempo, os programas de debate e de grande entrevista evoluíram por ciclos bem delimitados: até 1995, valorizaram a esfera pública, nomeadamente a esfera pública política; de 1996 até 1999 privilegiaram o espaço privado, cujas problemáticas - apresentadas pelo cidadão comum, mas debatidas predominantemente por especialistas - foram discutidas com códigos intrínsecos ao domínio

${ }^{1}$ A RTP adoptaria um formato semelhante em 2005, altura em que estreou Centro de Saúde, coordenado e apresentado por Cláudia Borges, a mesma jornalista que exercera essas funções em Ficheiros Clínicos. 
público; entre 2000 e 2003, os canais privados apresentaram formatos centrados na esfera íntima dos convidados e o canal público recentrou a sua informação semanal no espaço público político. Se actualmente nos movimentamos num espaço público cada vez mais privatizado e num espaço privado cada vez mais publicitado, a informação semanal dos canais generalistas portugueses nem sempre soube incorporar essas mudanças, nomeadamente nos debates, espaços propícios à reflexão desse dimensionamento da relação público/privado.

No que diz respeito aos convidados deste género de programas, em termos gerais, os que tiveram mais visibilidade na informação semanal nestes anos foram os políticos. Poder-se-ia dizer que a RTP1 foi quem mais privilegiou este grupo. Em parte, assim aconteceu, mas convém sublinhar que no início do segundo quinquénio dos anos 90 a classe política perdeu um espaço substancial, em grande parte por acção de Maria Elisa, que influenciou o formato similar da SIC Esta Semana. Num contexto de ausência de programas de informação nos canais privados, ou seja, depois de 2000, a estação pública recentrou-se nos políticos, excluindo dos seus plateaux vastas camadas da sociedade portuguesa. Esses distintos ciclos coincidem com determinados contextos: a predominância dos políticos em programas de informação semanal registou-se quando o Governo pertencia ao PSD e o desvio para temas sociais e interlocutores situados fora do campo político ocorreu com um Governo PS. Paralelamente aos políticos, os representantes de associações/sindicatos também foram muito solicitados para os debates televisivos, embora em menor número. Se os primeiros assumiam o poder instituído, os segundos representavam uma espécie de contrapoder que, no entanto, integrava o statu quo, fazendo com que os plateaux informativos fossem uma espécie de eco do poder dominante da sociedade.

$\mathrm{Na}$ análise dos programas de debate e de grande entrevista, verificámos que não houve preocupações substanciais em integrar o cidadão comum nas discussões televisivas, o que poderá ser paradoxal para canais de natureza generalista. Talvez se tenha julgado (erradamente) que bastava, de quando em vez, abordar situações com as quais os telespectadores estivessem relacionados, mantendo as audiências sob o estatuto de consumidoras (receptores passivos) de conteúdos. Essa deslocação da posição de cidadão para a de consumidor não só revela uma crescente miopia do sistema informativo em relação à dinâmica do sistema social como nega os traços que se reivindicam para a TV que sucedeu à fase do monopólio. No que à informação semanal diz respeito, o cidadão comum não esteve no centro da enunciação televisiva como se afirma quando se refere a fase correspondente à privatização do audiovisual, que Umberto Eco (1993) designa como "neotelevisão". Também não foi parte activa na programação informativa, mesmo na fase das novelas da vida real que, segundo Eliseo Veron (2001), inaugura formas de comunicação activas com os respectivos receptores (a audiência passa a ser entendida como público). Ao fazer uma gestão da palavra pública circunscrita a grupos restritos de notáveis, a informação semanal dos canais generalistas portugueses, para além de ter colocado alguns obstáculos à evolução do audiovisual, estagnou a dinâmica do espaço televisivo. Ao longo desses anos, deparámo-nos frequentemente 
com queixas, por parte de jornalistas que apresentavam programas de informação semanal, de uma conjuntura que o seu próprio trabalho fomentava: a falta de interlocutores com capacidade de intervir em determinados debates. A informação semanal afundava-se, assim, na espiral do silêncio que ela própria motivava.

A preferência que os debates e as entrevistas concederam às elites políticas, aos representantes de importantes instituições e a interlocutores com profissões de prestígio poderá explicar-se através de diversos factores: pelo facto de as emissões destacarem temas que ocupam o topo da actualidade noticiosa e por esta ser em grande parte construída a partir das esferas do poder (sobretudo político); pela preferência pelos macro-temas que permitem uma escolha mais ampla e, por isso, mais arbitrária de convidados; pela valorização que os jornalistas fazem das elites. Entre 1993 e 2005, muitos interlocutores ocuparam os plateaux de programas de informação não só pela competência que o seu posicionamento institucional/profissional lhes assegurava, mas sobretudo pela notoriedade que capitalizavam. Para além de serem capazes de falar acerca do tema em destaque, muitos daqueles a quem se concedeu o direito à "palavra televisiva” apresentavam algumas destas características:

- discurso fluente e expressivo;

- possibilidade de falar em nome de terceiros;

- telegenia/rentabilidade mediática;

- notoriedade pública ou, na ausência dela, capacidade de prender as audiências através daquilo que diziam.

Os requisitos que se exigiam àqueles que participavam em programas de debate ou de grande entrevista excluíam, à partida, muitos grupos de pessoas. Significará isso que, dois séculos depois de se constituir como um espaço público vedado àqueles que não sabiam fazer uso da razão, actualmente essa exclusão continua a reproduzir-se num espaço que se pretende que seja do grande público, como ambiciona ser a televisão generalista? Se a extensão da razão no espaço público do século XVIII havia excluído a grande massa daqueles que se encontravam privados de competências intrínsecas a um eficaz uso da razão, a organização televisiva deste novo espaço social que os programas televisivos constroem fará o mesmo dois séculos mais tarde? Nos programas de informação, haverá cidadãos mais legítimos do que outros? Se tivermos em conta o que se passou entre 1993 e 2005 na informação semanal dos canais generalistas portugueses, a resposta a estas perguntas é afirmativa.

\section{Uma oportunidade perdida para fomentar um espaço público televisivo dinâmico, diversificado, acessível e próximo do quotidiano}

Poder-se-á argumentar que o surgimento dos canais temáticos no cabo, nomeadamente da SIC Notícias, que começou a emitir em 2001, se constituía como o espaço propício a formatos mais alargados de informação que, a partir de 2000, deixaram de caber na grelha nocturna da SIC. É verdade que programas como Ficheiros Clínicos e Esta 
Semana foram transferidos para o canal do cabo, depois de um tempo considerável de emissão na estação privada generalista. No entanto, parece-nos muito redutor o argumento que contrapõe a oferta dos canais temáticos para justificar determinadas falhas das estações que operam em sinal aberto. O que estará em causa serão dois canais com um funcionamento distinto, com audiências diferentes, com acesso desigual por parte das várias regiões do país. Se as lógicas fossem de complementaridade, quais as razões que justificariam o Jornal da Noite da SIC ou o Telejornal da RTP, se a SIC Notícias e a RTPN têm serviços informativos de manhã até, pelo menos, à meia-noite? Outro argumento a aventar para o desaparecimento da informação semanal dos ecrãs generalistas privados poderia ser a absorção, pela informação diária, de determinados géneros, nomeadamente os da grande reportagem e do debate (político). É verdade que, a partir de 2001, os noticiários da noite da RTP, SIC e TVI integraram no seu alinhamento alguns trabalhos de grande reportagem e criaram rubricas específicas para o comentário político, feito por políticos dos principais partidos portugueses (PS e PSD). Se no caso da grande reportagem nunca houve uma regularidade na emissão desses trabalhos jornalísticos, no caso do comentário político tratou-se de espaços efémeros pontuados por alguma controvérsia devido à filiação partidária dos respectivos comentadores e apresentados como se de verdadeiros espectáculos da palavra se tratasse ${ }^{2}$. Esses espaços serão, pois, muito diferentes dos debates televisivos, que se desenvolvem por critérios jornalísticos, obedecendo ao princípio do contraditório, confrontando diversos pontos de vista, moderados por jornalistas que procuram o equilíbrio das intervenções.

Neste tempo de "mcdonaldização do sistema audiovisual" (Blanco Sampedro, 2003), a televisão generalista parece mais interessada em exibir-se e promover-se a si própria, prescindindo do contacto com o mundo exterior. "Tele-realidade", "tele-verdade" ou "espectáculo do real televisivo" assumem-se como conceitos recorrentes para falar da TV actual, onde a verdade dos enunciados cede lugar à verdade da enunciação. O visível sobrepõe-se ao inteligível, o emocional ao racional. Mas, como lembra Régis Debray (1991), "ver” não é sinónimo de “entender”. É exactamente a partir deste postulado que a informação televisiva deve procurar espaço para recuperar o terreno perdido nestes últimos anos. Percorrendo o horário nobre dos canais generalistas portugueses desde Setembro de 2000 (altura em que se estreou o Big Brother na TVI), os programas de informação semanal foram desaparecendo das estações privadas. Serão os telejornais suficientes para perceber o que se passa de mais importante? Constituindo-se como fragmentos da actualidade, as respectivas peças noticiosas terão capacidade para nos situar na complexidade daquilo que nelas

\footnotetext{
${ }^{2} \mathrm{O}$ exemplo de maior longevidade no comentário feito no interior do noticiário foi o de Marcelo Rebelo de Sousa, que, de Maio de 2001 até Outubro de 2004, manteve o seu comentário no Jornal Nacional de domingo da TVI, abandonando a estação na sequência de uma polémica desencadeada pelas críticas do Governo (do seu próprio partido), liderado por Pedro Santana Lopes, que tornou público o seu desagrado em relação a essas intervenções. Na noite das eleições legislativas, a 20 de Fevereiro de 2005, Rebelo de Sousa estrear-se-ia na RTP1 com idênticas funções, dispondo, ao domingo, de uma rubrica autónoma do Telejornal, intitulada As Escolhas de Marcelo.
} 
é sumariamente relatado?

Já sabemos que a actualidade noticiosa é sempre uma selecção de acontecimentos, mas convém que o filtro por onde passam os factos que acedem à visibilidade mediática reflicta o mundo onde nós vivemos e não apenas o universo televisivo, fazendo-nos crer que nada mais se passa para além daquilo que é criado no pequeno ecrã. Por outro lado, os avanços que o jornalismo televisivo tem feito em relação aos territórios do domínio privado levantam a questão de saber se essa aparente transparência confere maior proximidade àquilo que se passa. Nem sempre o excesso de luz permite a melhor visibilidade, o que valoriza o discurso enquanto âncora imprescindível para aquilo que se vê. Mas é essa atracção pela hiper-visibilidade, desligada de qualquer contextualização, que a TV tem vindo a promover através sobretudo dos novos reality shows. E que o jornalismo televisivo não tem sido capaz de inverter, procurando outras formas de explicar a realidade que ultrapassem a hipertrofia representativa que resulta de uma cultura assente na profusão de imagens e na escassez da palavra.

Reflectindo sobre o jornalismo no século XXI, José-Luís Martinez Albertos (1999) afirma que "a possível sobrevivência do jornalismo está em grande parte condicionada pela valorização da actividade jornalística como profissão", devendo esse trabalho assentar em dois pilares: assumir-se como um direito público e ser regulado por exigências éticas criadas pelos próprios profissionais. Seria utópico reclamar uma programação informativa como aquela que era praticada ainda num passado recente. Vive-se um tempo diferente. Um tempo em que a vida pública se mistura com o espaço privado e em que a intimidade é exposta como se de um assunto social se tratasse. Um tempo em que os indivíduos se constroem não só através de discursos racionais, mas em que se percebem, a eles e aos outros, através de registos emotivos. Mais do que modos de pensar, procuram-se modos de sentir. Neste contexto, a informação televisiva vê-se perante o desafio de renovar os seus códigos de enunciação televisiva. Nos últimos anos, optou-se pelo caminho mais fácil. E mais perigoso. Rasgaram-se os limites da intimidade, promoveu-se o voyeurismo, criaram-se pseudo-notícias e instalou-se uma espécie de "jornalismo de causas", subserviente face às leis do mercado, perdendo de vista o bem comum. Se hoje se insiste em manter o jornalismo televisivo como um campo social autónomo, de que práticas e de que valores se poderá falar? Será que ainda faz sentido haver redacções com profissionais de jornalismo? Será que necessitamos hoje de jornalistas que privilegiem factos de interesse público, que promovam um debate plural e igualitário, que procurem informação junto de fontes credíveis, que respeitem o princípio do contraditório...? Será que queremos apenas divertir-nos, quando ligamos a TV? Será que não nos fará falta uma informação que seja simultaneamente de interesse do público, mas também de interesse público? Se as respostas parecem óbvias, não serão paradoxais as opções que os responsáveis pela programação dos canais generalistas tomaram entre 1993 e 2005, principalmente nos primeiros anos do século XXI? 


\section{Notas finais}

A televisão é alvo de múltiplas e, frequentemente, severas apreciações, mas essas vozes críticas que pululam no espaço público quase nunca têm um papel efectivo na mudança das práticas de quem decide a programação ou os conteúdos de determinada emissão. Os políticos da oposição costumam falar, muitas vezes por comodidade e interesses particulares, na manipulação que o Governo exerce sobre a televisão pública, particularmente sobre os programas de informação. Em artigos de opinião, há quem aponte, aqui e ali, os excessos de determinado programa. Recorde-se, por exemplo, os textos de protesto contra o Big Brother, aquando da sua estreia. O que mudou com tudo isto? Muito pouco. O que significa que o caminho terá de ser outro.

Certamente que será aconselhável favorecer todos os mecanismos de auto-regulação, desde que eficazes, consensuais e respeitadores da lei vigente. Paralelamente a isto, as entidades reguladoras têm também de encontrar outras formas para desenvolver a sua actuação. Não basta tornar públicas sucintas deliberações, nem tão-pouco será admissível que tais decisões surjam após longos dias, no passado foram meses ou anos (!), de espera. É preciso fomentar uma monitorização permanente do trabalho dos media e, com esses dados, desenvolver estudos rigorosos não só ao nível da produção como também da recepção. Na nossa opinião, será mais produtivo demonstrar do que acusar. E os retratos daquilo que poderemos obter com essas análises, para além de insuspeitos, podem ser surpreendentes e benéficos para todos.

\section{Bibliografia}

Blanco Sampedro, V. (2003) 'La McTele como industria de identidades lucrativas y de consumo. Análisis de Gran Hermano y Operación Triunfo', in Blanco Sampedro, V. (ed.). (2003) La Pantalla de las Identidades, Barcelona: Icaria.

Camps, V. (1998) El Siglo de las Mujeres, Madrid: Ed. Cátedra.

Debray, R. (1991) Cours de Médiologie Générale, Paris: Gallimard.

Eco, U. (1993) Viagens na Irrealidade Quotidiana, Lisboa: Difel.

Habermas, J. (1986) Historia y Crítica de la Opinión Pública: la transformación estrutural de la vida pública, México: Ed. Gili.

Gil, J. (2005) Portugal, Hoje. O medo de existir, Lisboa: Relógio d' Água.

Lopes, F. (2005) "Uma década de televisão em Portugal (1993-2003) Estudo dos programas de informação semanal dos canais generalistas", tese de doutoramento apresentada na Universidade do Minho, Dezembro.

Martinez Albertos, J. (1999). 'El Periodismo en el siglo XXI: mas allá del rumor y por encima del caos' in Estúdios sobre el mensage periodístico, $\mathrm{n}^{\circ}{ }^{\circ}$.

Veron, E. (2001) "Les publics entre production et réception: problèmes pour une théorie de la reconnaissance", Conferências da Arrábida, 27 a 31 de Agosto (texto policopiado).

Leis e Deliberações

Contratos de Concessão do Serviço Público de Televisão celebrados 2003

Lei da Televisão: Lei n. ${ }^{\circ}$ 32/2003, de 22 de Agosto. 